\title{
The role of metaboreceptor on exercise in hyperthermic environment with college basketball players
}

Hyun-Gook Kim, Jong-Kyung Kim, Kyung-Ae Kim, Hosung Nho, Sungchul Lee, Myoung-Jae Chang and Hyun-Min Choi

\begin{abstract}
The objective of this study is to review physiological differences of college basketball players cardiovascular responses and group IV metaboreceptor interactions appearing post muscular ischemia exercise (PEMI) caused by a static handgrip exercise (SHE). The subjects were placed in a temperature and moisture stabilized indoor environment for $2 \mathrm{~h}$ in order to measure blood pressure. For the SHE, maximal voluntary contraction of arms with a relative strength of $50 \%$ of the maximum muscular strength was put into isometric training for $2 \mathrm{~min}$. After completing the exercises, cuffs worn on the arms of the subjects were pressurized up to $200 \mathrm{mmHg}$ by applying PEMI to block the artery and vein. In this way, the cardiovascular responses created by SHE and PEMI were measured. Blood samples of subjects were collected from the vein of each upper arm before SHE and after PEMI to measure the metabolite hormone and catecholamine in the blood. Results from the measurements showed a significant decrease of blood pressure under high temperature environments compared to normal temperature environments. With respect to PEMI, increases in blood pressure under the high temperature environment were significantly lower compared to the normal temperature environment. In conclusion, this study revealed that college basketball players with good physical strength had higher sensitivities of arterial baroreceptor. However, blood pressure was not increased accordingly because the increase of cutaneous vasoconstriction due to stimuli of the metaboreceptor under a high temperature environment could not be compensated by arterial baroreflex due to the increase of total vascular conductance.
\end{abstract}

Keywords: Metaboreceptor, Total vascular conductance, Temperature environment, Blood pressure, College basketball player

\section{Background}

It is known that the human body uses $20 \%$ of produced energy for the function of the tissue and contraction. The other $80 \%$ of produced energy are converted into heat. To maintain core temperature, the heat generated needs to radiate to the skin exposed to the surrounding environment through blood flow. Heat between the human body and the surrounding environment is constantly transferred to maintain the core temperature. When body temperature increases, cutaneous blood vessels are vasodilated (Wilmore et al. 2008), leading to the

*Correspondence: hmchoi92@khu.ac.kr

Graduate School of Physical Education, KyungHee University,

Seocheon-dong Giheung-gu, Yongin-si, Gyeonggi-do 446-701, Korea relaxation of cutaneous blood vessels. Heat is then emitted from the skin and sweat glands simultaneously to keep our body temperature at its normal level.

In a hyperthermic environment, exercise demands increased blood volume of the skin to radiate heat (Rowell and Blackmon 1986; Rowell et al. 1986), resulting in decreased blood volume returning into the heart. Simultaneously, exercise in a hyperthermic environment increases the cardiac output (CO) to increase blood volume to skeletal muscles, resulting in decreased blood volume into the liver, kidney and skin due to the redistribution of the amount of CO (Crandall 2000). During exercise in a hyperthermia environment, simultaneous physiological responses to increase the blood volume into skin and skeletal muscles. Exercise increases $\mathrm{CO}$ and blood volume
Springer Open

(c) 2016 Kim et al. This article is distributed under the terms of the Creative Commons Attribution 4.0 International License (http:// creativecommons.org/licenses/by/4.0/), which permits unrestricted use, distribution, and reproduction in any medium, provided you give appropriate credit to the original author(s) and the source, provide a link to the Creative Commons license, and indicate if changes were made. 
into liver, internal organs, kidney, and skin. However, continued exercise in a hyperthermia environment increases the blood volume constantly into skin to radiate heat, which decreases $\mathrm{CO}$ and exercise performance. The exposure to hyperthermia environment causes syncope due to decreased blood pressure when compared to a normothermic environment because a lot of blood needs to be redistributed into the skin to release heat (Wilmore et al. 2008). Arterial baroreceptor plays an important role in the control of blood pressure. Aerobic exercise training is reported to improves the function of the arterial baroreceptor (Goldberg et al. 2011; Gulli et al. 2003). Although it is known that the arterial baroreceptor function is decreased in a hyperthermic environment (Crandall 2000), not enough research is performed to study the function of arterial baroreflex and the metabolic receptor when well trained athletes are exposed to a hyperthermic environment.

During exercise, sympathetic nerve activity (SNA) increases, followed by the increase of $\mathrm{CO}$, heart rate (HR), blood pressure (BP), and vasoconstriction. These increases are controlled through the following three neural mechanisms: (1) The central command anticipates the exercise and stimulates the cerebral motor cortex, then contracts skeletal muscle and stimulates the activates the cardiovascular control circuits at the same time. The stimulation of this brain stem decreases parasympathetic neural activities, resulting in the increase of SNA, BP, and HR; (2) The increases are regulated by the arterial baroreflex which affects the sympathetic nerve and the parasympathetic nerve at rest or during exercise, which then controls HR, stroke volume (SV), and peripheral blood vessels. This control regulates the blood pressure at every single moment (DiCarlo and Bishop 1992); (3) The increases are controlled by exercise pressor reflex (EPR). EPR is the feedback mechanism delivered from the afferent nerve stimulation of the skeletal muscle group III and group IV receptors during contraction and stretch of the skeletal muscle. Group III mechanoreceptor is stimulated by the muscle contraction and group IV metaboreceptor is stimulated through the metabolite accumulation for exercise. This afferent nerve stimulation increases the blood pressure, $\mathrm{HR}, \mathrm{CO}$, and total peripherial resistance (TPR) during exercise (Hayes and Kaufman 2001; Hayes et al. 2005; Stebbins et al. 1988). This study focuses on the neural mechanism of group IV metaboreceptor of the skeletal muscle and the function of arterial baroreflex. It has been reported that the stimulation of the metaboreceptor through static handgrip exercise (SHE) and post exercise muscle ischemia (PEMI) in the normothermic environment or in the hyperthermia environment increases the skin SNA and decreases the cutaneous blood volume (Saito et al. 1990; Vissing and Hjortso 1996; Vissing et al. 1991). Opposite research result is reported that the metaboreceptor stimulation does not affect the cutaneous SNA or contraction of the cutaneous blood vessels (Ray and Wilson 2004). Arterial baroreflex plays a role in the compensation of the increase of blood pressure stimulated by the metaboreceptor. It has been demonstrated that people who have great cardiorespiratory endurance are highly sensitive to arterial pressure (Kim et al. 2005a, b; Raczak et al. 2006).

However, research on exercise and cardiovascular response stimulated by the metaboreceptor using in well trained athletes during a hyperthermic environment is lacking. In addition, arterial baroreceptor in a hyperthermic environment affects muscle metaboreceptor sensitivity is currently unknown. Therefore, this study was designed to examine the difference in physiological response and cardiovascular response at PEMI by SHE in normothermic and hyperthermia environments. In addition, this study determined how arterial baroreceptor would affect muscle metaboreceptor of college basketball athletes in a hyperthermic environment.

\section{Methods}

\section{Experimental approach to the problem}

To obtain reliability of measured data with regard to conditions, data were collected from athletes without any basketball training during off-season. We used the environmental chamber system (The Low Pressure and Hypoxia Center, Yongin, Korea) to set up a goal temperature for the normothermic and hyperthermic environment that might affect blood pressure and body composition since the day before the first visit were controlled. Subjects were exposed to room temperature for up to $2 \mathrm{~h}$ to maintain a constant temperature and relative humidity in the normothermic environment setting. After that, body composition, resting blood pressure, and core temperature were measured in subjects as pretest. The core temperature was measured directly through the anus using skin temp and humidity logger (Technox, China). The maximal voluntary contraction (MVC) of the dominant forearm was tested by having subjects squeeze a handgrip dynamometer device (Takei 880, Japan) at maximal effort three times. The highest value was used as MVC. The MVC was used to calculate the relative exercise intensity of $50 \%$ for the experimental protocol. All subjects rested quietly in a chair for at least $5 \mathrm{~min}$ and then performed a static handgrip exercise (SHE) by using the principle of isometric training to complete the full 2 min at $50 \%$ of MVC. After SHE, blood pressure cuff induced by inflation was placed around the upper arm to suprasystolic level $(\sim 200 \mathrm{mmHg})$ for application of PEMI (Shibasaki et al. 2001).

The cuff was inflated immediately before the end of SHE for 2 min. Participants' cardiovascular responses 
were measured by the method explained above during SHE and PEMI. Examiner collected blood from subjects to measure blood metabolic hormones (lactic acid, La; potassium, $\mathrm{K}^{+}$) and catecholamine (epinephrine and norepinephrine) in brachial vein before SHE and after PEMI. $48 \mathrm{~h}$ after pretest in the normal temperature environment, all tests were performed in subjects exposed to the hyperthermic environment, including the resting blood pressure, the core temperature, the cardiovascular response during SHE and PEMI, and the responses of blood metabolic hormones and catecholamine.

\section{Study population}

The experiments were performed using 20 healthy college basketball players (age $20 \pm 0.2$ years). Prior to any intervention, subjects were instructed to abstain from alcohol, caffeine, and strenuous exercise for $24 \mathrm{~h}$. Informed consents were obtained from all subjects before participating. All procedures were reviewed and approved by the Kyung Hee University Institutional Review Board (KHU 2014-19).

\section{Measurement of body composition variables and core temperature}

Subjects were asked to remove any metals, such as jewelry and watch, and stand on the measuring board to determine body composition. Bioelectric impedance method (X-scan Plus II, Korea) was used to measured height, body weight, fat mass, fat free mass, and body fat percentage. In addition, blood pressure was measured by using mercury sphygmomanometer at $10 \mathrm{~min}$ after subjects arrived at the laboratory. Examiner measured systolic blood pressure (SBP) and diastolic blood pressure (DBP) twice at $10 \mathrm{~min}$ intervals environments (Table 1).

To measure the core body temperature according to different temperature environments, participants stayed on the environmental chamber system to maintain a constant temperature and relative humidity of the two conditions. The normothermic condition (NC) was $22-23{ }^{\circ} \mathrm{C}$, $50 \%$ of relative humidity (Shibasaki et al. 2001). The hyperthermic condition (HC) was $35{ }^{\circ} \mathrm{C}, 50 \%$ of relative humidity (Kondo et al. 2000). The core temperatures were measured directly through the anus using skin temp and humidity logger (Technox, China) after subjects have been exposed for up to $2 \mathrm{~h}$ in a comfortable condition in each.

\section{Measurement of cardiovascular responses}

Stroke volume (SV), heart rate (HR), SBP, and DBP were continuously measured on a beat-by-beat basis using a Finometer device (Finometer, Finapres Medical Systems, Netherlands). This device uses the Model-flow method to compute a waveform from peripheral arterial
Table 1 Physical characteristics of subjects

\begin{tabular}{lc}
\hline Variables & Subjects $(\mathbf{n}=\mathbf{2 0})$ \\
\hline Age (years) & $20 \pm 0.2$ \\
Height $(\mathrm{cm})$ & $189.0 \pm 1.9$ \\
Body weight $(\mathrm{kg})$ & $80.4 \pm 1.8$ \\
BMI $\left(\mathrm{kg} / \mathrm{m}^{2}\right)$ & $22.6 \pm 0.3$ \\
SBP $(\mathrm{mmHg})$ & $117 \pm 2.7$ \\
DBP $(\mathrm{mmHg})$ & $63 \pm 2.8$ \\
MAP $(\mathrm{mmHg})$ & $78 \pm 3.1$ \\
Resting HR (beat/min) & $60 \pm 1.6$ \\
MVC (kg) & $49.0 \pm 1.4$ \\
\hline
\end{tabular}

Values are expressed as mean \pm standard error

$B M I$ body mass index, $S B P$ systolic blood pressure, $D B P$ diastolic blood pressure, $M A P$ mean arterial pressure, $H R$ heart rate, MVC maximum voluntary contraction

pressure to accurately track acute changes in BP and SV via simulation of a non-linear three-element model of vascular input impedance (Bogert and van Lieshout 2005). Arterial BP was measured at the middle finger of the non-dominant hand with the hand positioned at the heart level using servocontrolled finger photoplethysmography. Because finger arterial BP may differ from standard BP measurements, brachial artery BP was also measured by a sphygmomanometer to establish accurate values of resting BP. Mean arterial pressure (MAP) was calculated using the following formula: MAP $=[(\mathrm{SBP}-$ DBP) $\times 1 / 3]+$ DBP. CO was calculated from the Fick Equation $(\mathrm{CO}=\mathrm{SV} \times \mathrm{HR})$. Total vascular conductance (TVC) was calculated as CO/MAP. Participants took SHE with previously MVC measuring arm in a comfortable sitting position for $2 \mathrm{~min}$. With previously measured MVC, subjects performed the gripping exercise at $50 \%$ relative intensity of MVC using a dynamometer (Kondo et al. 2003). Participants were instructed to perform the exercise whilst deep breaths. PEMI method has been used to provoke muscle metaboreflex in clinical demonstration (Sausen et al. 2009; Sinoway et al. 1989). To provoke muscle metaboreflex, we blocked brachial vein through increasing the pressure of the cuffs to $200 \mathrm{mmHg}$ by placing the blood pressure cuff on participant's brachial vein after SHE. The blocking continued for $2 \mathrm{~min}$. Participants were instructed to keep their normal breathing during the blockade of brachial vein and artery.

\section{Measurement of metabolic hormones and catecholamine}

Blood sampling was performed after fasting for at least $8 \mathrm{~h}$ (empty stomach). Examiner collected $3 \mathrm{ml}$ of blood from the forearm cardinal vein of each subject using a 22 gauge injection needle. Blood samples were collected from each participant a total of three times using catheter, once per condition (resting, SHE, and PEMI). Blood 
collecting at the resting condition was carried out when subject visited the laboratory and took a rest for at least $10 \mathrm{~min}$. Examiner also gathered blood using previously inserted catheter immediately after measuring blood pressure at SHE and PEMI. Immediately after collecting the La and $\mathrm{K}+$ in EDTA tube, blood samples were degraded to collect plasma by centrifugation at $3000 \mathrm{rpm}$ for $10 \mathrm{~min}$. Collected plasma samples were kept after rapid cooling at $-70{ }^{\circ} \mathrm{C}$ until ingredient analysis. La was determined by chemiluminescence immunoassay (Cobas Integra-800, Switzerland), and $\mathrm{K}^{+}$by an ion selective electrode assay (Rapodchem 744-Siemens, Germany). Epinephrine and norepinephrine were measured by high performance liquid chromatography (HPLC) method using Acclaim (Bio-Rad, USA) and Plasma catecholamine (Bio-Rad, Germany).

\section{Statistical analyses}

Values of the all items to describe statistics quantity (mean \pm standard error) were calculated using Sigma Stat 11.0 program. Cardiovascular responses and plasma concentrations for blood analysis were analyzed using a two-way ANOVA with repeated measures for comparison. If a significant interaction was found, post hoc tests were performed by Tukey's test. Paired $t$ test was used to compare the mean difference regarding the cardiovascular responses and the blood analysis data at rest, SHE, or PEMI in different environments. Statistically significant difference was considered when p-value was less than .05 .

\section{Results}

Resting MAP was statistically significant different in the normothermic to the hyperthermic environment $(p<0.05)$. HR and SV were increased slightly but not statistically significant different in both environments. However CO and TVC were statistically significant different in the normothermic to the hyperthermic environment $(p<0.05)$. However, the core temperature at a resting condition in the hyperthermic environment was significantly lower than that in the normothermic environment (Table 2).

During SHE as contrasted with the resting, $\triangle \mathrm{MAP}$ was statistically significant different in the normothermic to the hyperthermic environment $(p<0.05)$. But $\Delta \mathrm{HR}, \Delta \mathrm{SV}$, and $\Delta \mathrm{CO}$ were not significantly increased in the normothermic to the hyperthermic environment. However $\triangle T V C$ were significantly increased in the normothermic to the hyperthermic environment $(p<0.05)$ (Fig. 1).

At PEMI, $\triangle$ MAP was not statistically significant different in the hyperthermic to the the normothermic environment. But $\triangle \mathrm{HR}, \triangle \mathrm{CO}$, and $\triangle \mathrm{TVC}$ were significantly increased in the hyperthermic to the normothermic environment $(p<0.05), \Delta \mathrm{SV}$ was not significantly decreased
Table 2 Physiological responses in the normothermic and the hyperthermic environment at resting

\begin{tabular}{lrr}
\hline Variables & \multicolumn{1}{c}{ NT } & \multicolumn{1}{c}{ HT } \\
\hline MAP $(\mathrm{mmHg})$ & $83 \pm 2.9$ & $79 \pm 1.6^{*}$ \\
HR (beat/min) & $64 \pm 2.6$ & $65 \pm 2.3$ \\
SV $(\mathrm{ml})$ & $110.2 \pm 4.6$ & $117.8 \pm 5.9$ \\
$\mathrm{CO}(\mathrm{L} / \mathrm{min})$ & $6.6 \pm 0.4$ & $7.6 \pm 0.4^{*}$ \\
TVC $(\mathrm{ml} / \mathrm{min} / \mathrm{mmHg})$ & $80.7 \pm 4.7$ & $96.1 \pm 5.5^{*}$ \\
Core body temperature $\left({ }^{\circ} \mathrm{C}\right)$ & $36.5 \pm 0.1$ & $37.2 \pm 0.1^{*}$ \\
\hline
\end{tabular}

Values are expressed as mean \pm standard error

$M A P$ mean arterial pressure, $H R$ heart rate, $S V$ stroke volume, $C O$ cardiac output, $T V C$ total vascular conductance, NT normal temperature, $H T$ high temperature

* Significantly different versus normal temperature

in the hyperthermic environment to the normothermic environment (Fig. 2).

Resting levels of norepinephrine and epinephrine were statistically different between normothermic and hyperthermic environment $(p<0.05)$. The concentration of La was significantly increased in the normothermic to the hyperthermic environment. However, the concentration of $\mathrm{K}^{+}$was significantly decreased in the normothermic to the hyperthermic environment $(p<0.05)$ (Fig. 3).

At PEMI, levels of norepinephrine and epinephrine were statistically different between normothermic and hyperthermic environment $(p<0.05)$. However, the concentration of $\mathrm{K}^{+}$was significantly decreased in the normothermic to the hyperthermic environment $(p<0.05)$ (Fig. 4).

\section{Discussion}

Heat exposure increases blood volume toward cutaneous region in a hyperthermic environment. Blood volume in a hyperthermic environment can be increased to $7500 \mathrm{ml} /$ min from $300 \mathrm{ml} / \mathrm{min}$ in a normothmic environment (Rowell and Blackmon 1986). At rest, it is important that $\mathrm{CO}$ increases along with TPR increases toward skin and other tissues (i.e. splanchnic, renal) to prevent excessively decreased blood pressure (Rowell and Blackmon 1986; Rowell et al. 1986). Exposure to a hyperthermic environment results in complex response to decreases or keep the blood pressure. Our study showed that MAP was significantly decreased in the hyperthermic environment because the blood vessels toward skin were relaxed. Total peripheral resistance (TPR) was decreased, although $\mathrm{CO}$ increased in the cardiovascular response of college basketball players at resting. There is increasing sympathetic activation to non-cutaneous bed to redistribute blood by increasing the blood volume toward skin (Cui et al. 2004; Keller et al. 2006). Generally, CO increment in a hyperthermic environment occurs through HR and SV 


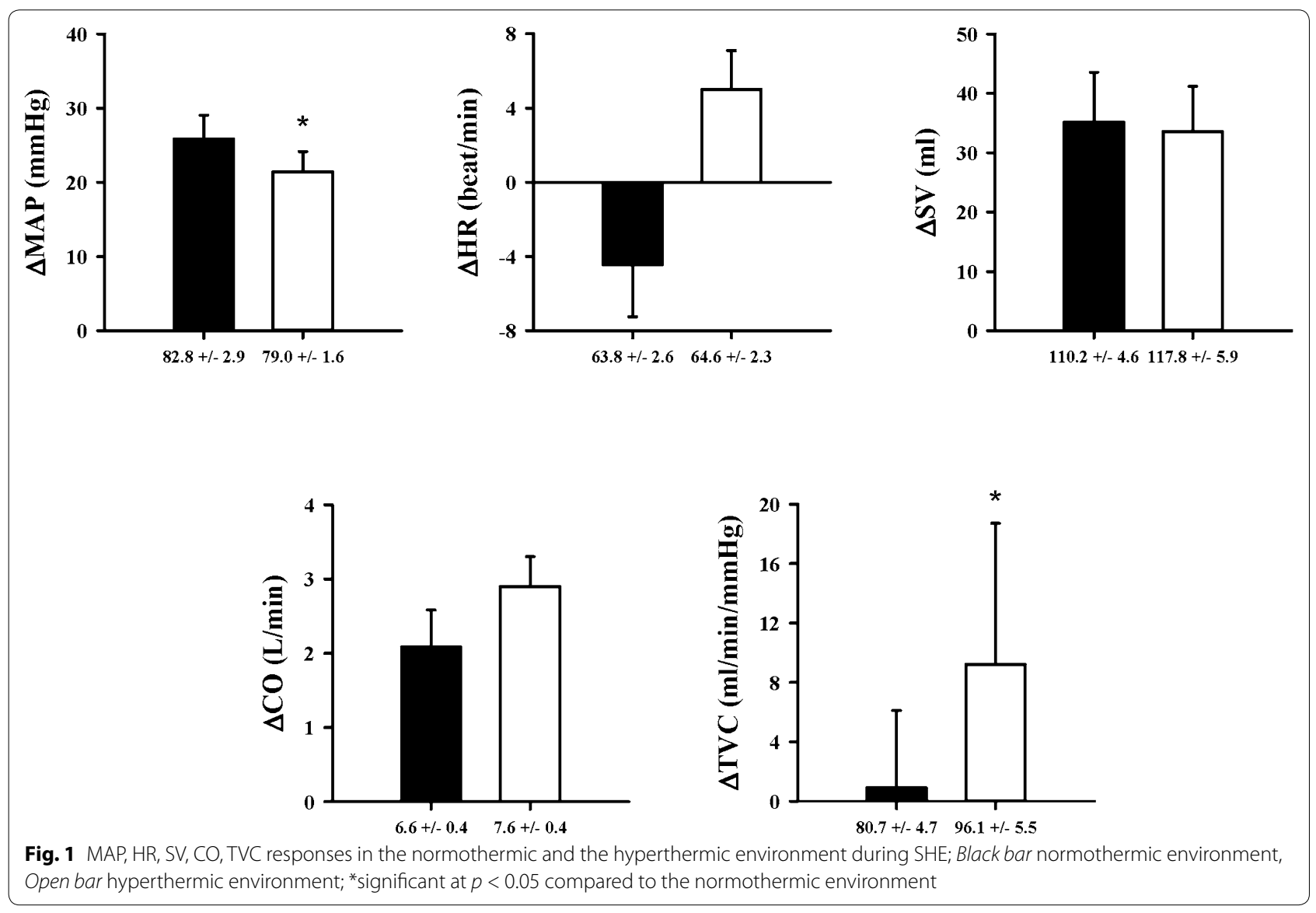

increase (Damato et al. 1968; Minson et al. 1998; Rowell et al. 1969). Our study revealed that CO increase was due to SV increase. Arterial baroreceptor performs an important function in regulating blood pressure. It has been reported that aerobic exercise training improves the function of the arterial baroreceptor (Goldberg et al. 2011; Gulli et al. 2003). However, the function of the arterial baroreceptor decreases in a hot environment. Although athletes who have higher aerobic fitness have been reported to have improved function of the arterial baroreceptor (Crandall 2000), arterial baroreflex was not able to increase to normal due to the decreasing blood pressure from the TPR decrease after exposure to the hyperthermic environment.

Exercise in the hyperthermic environment increased blood volume to the skin to maintain body temperature. $\mathrm{CO}$ was increased to meet this demand. However, there is a limitation of increase in a CO. It is the most challenging issue in the regulation of cardiovascular response to maintain homeostasis in such situation. Abnormal cardiovascular response occurs when untrained persons perform a prolong exercise at a high intensity in a hyperthermic environment (Crandall and González-Alonso
2010). On the other hand, well-trained athletes are adapted to cardiovascular response for exercise in a hyperthermic environment. Usually, the modified cardiovascular response during exercise in a hyperthermic environment occurs in mid to high intensity. Such responses include the decrease of SV, central venous pressure, blood pressure, and CO. However, continuous exercise in a low to moderate intensity maintains or increases $\mathrm{CO}$ level (Armstrong et al. 1987; Laughlin and Armstrong 1983). Our study revealed a statistically significant increase in $\mathrm{CO}$ and TVC in MAP in the hyperthermic environment compared to the normothermic environment. However, no significant difference in the blood pressure response was found between the two environments. These results suggest that enough $\mathrm{CO}$ increase and TPR decrease might have maintained the blood pressure level because participants were well-trained basketball player who performed low-intensity exercises instead of high-intensity in this study. We suggest that the decrease of the blood pressure could occur because TPR decreased to emit heat for exercise in the hyperthermic environment.

In our study, the brachial artery and vein were occluded by a blood cuff immediately after the static exercise to 

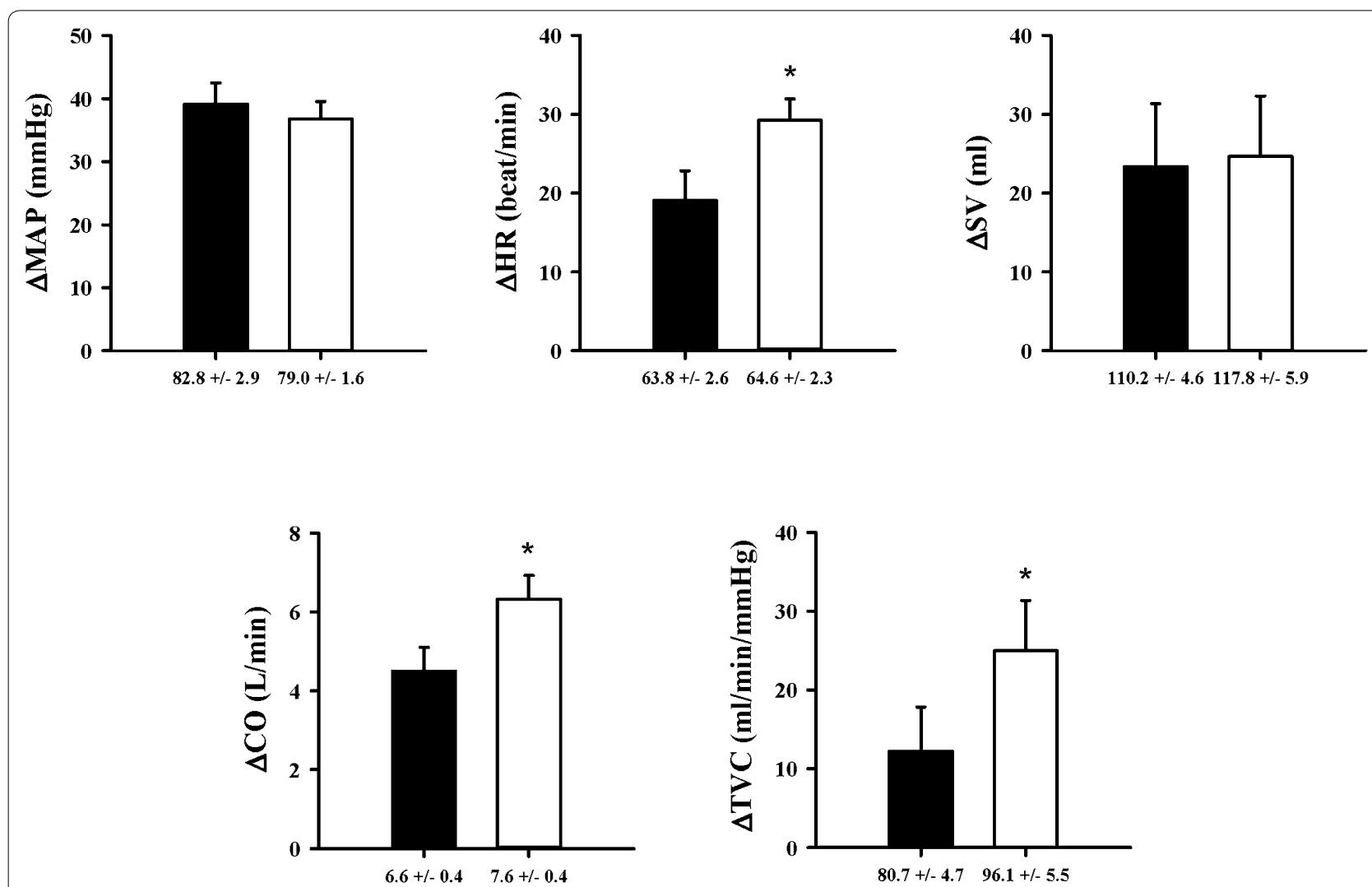

Fig. 2 MAP, HR, SV, CO, TVC responses in the normothermic or hyperthermic environment at PEMI; Black bar normothermic environment; Open bar hyperthermic environment; ${ }^{*}$ significant at $p<0.05$ compared to the normothermic environment

stimulate only metaboreceptors without the effect of the central command and the mechanoreceptors. Metaboreceptor stimulation increases blood pressure with SNA through vascular obstruction. It has been reported that exercise in normal temperature affects blood pressure by $\mathrm{CO}$ increase rather than overall TPR increase (Choi et al. 2013; Kim et al. 2005a, b). The stimulation of the skeletal muscle metaboreceptors in the hyperthermic environment does not affect the conduction of nonglabrous cutaneous blood vessels (i.e., hairy skin), whereas the conductance of glabrous cutaneous blood vessels decreases (i.e., nonhairy skin) (Kondo et al. 2003). Blood pressure responses vary depending on the long-term training type. Amano et al. (2011) compared blood pressure responses among male sprinters, male distance runners, and untrained males during PEMI to examine skeletal muscle metaboreceptor in a hyperthermic environment and found that the sprinter group had significantly increased MAP during stimulation of the metaboreceptor compared to the distance runner group or the untrained group. Significant increase of MAP in the sprinter group could be due to the fact that the sprinters have more metabolite accumulation due to their fast developed twitch muscles. In agreement with the results of previous studies, our study also revealed that blood pressure increased through the stimulation of metaboreceptor in the normal temperature and increase of $\mathrm{CO}$. Metaboreceptor stimulation did not affect the conductivity alteration of the cutaneous blood vessels. The cutaneous blood vessels were relaxed, TPR was decreased, and blood pressure was less increased to emit heat. Kim et al. (Kim et al. 2005a, b) stimulated a living dog's metaboreceptor through the vascular obstruction after removing the arterial baroreflex to examine how the arterial baroreflex and the metaboreflex interacted with each other. They found that increased blood pressure through stimulation of the metaboreceptor almost doubled compared to that before the removing of arterial baroreflex. They also found increase of CO and TPR caused excessive blood pressure increase after the removing of arterial baroreflex. Their study demonstrated that the blood pressure increase by metaboreflex absorbed shock through the arterial baroreflex, which offsets SNA whereby stimulated the peripheral blood vessel. Our study results were in consistent with previous research finding that blood pressure increase by the metaboreflex in a hyperthermic 

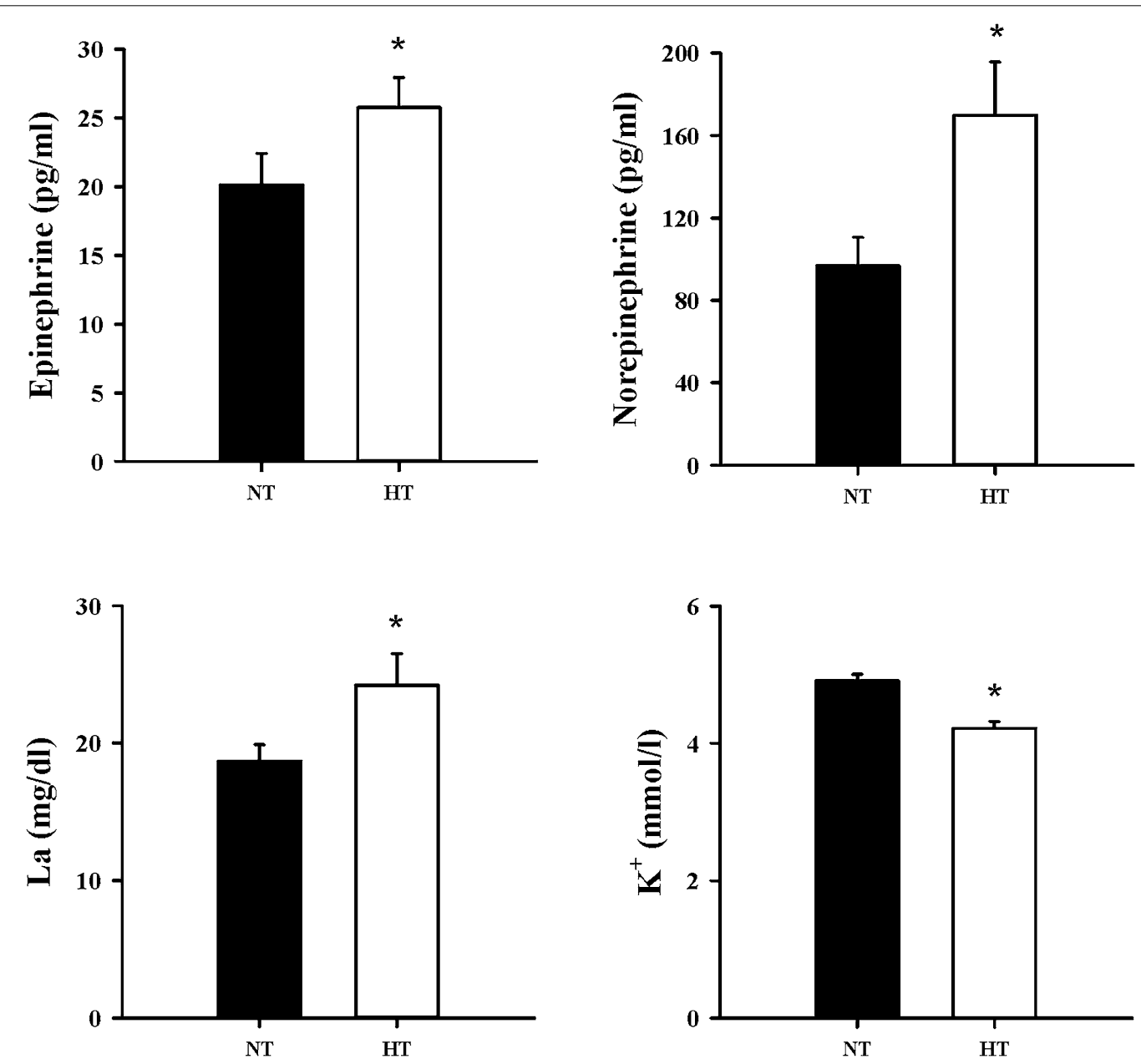

Fig. 3 Epinephrine, norepinephrine, La, $\mathrm{K}^{+}$concentrations in the normothermic and hyperthermic environments at resting. NT normothermic environment, HT hyperthermic environment; ${ }^{*}$ significant at $p<0.05$ compared to the normothermic environment

environment is less increased compared to that in a normothermic environment (Crandall 2000). We anticipated that the blood pressure would increase through increased TPR resistance because the function of the arterial baroreflex would be decreased in a hypertehmic environment. However, the opposite result was found. Although this study did not find the clear mechanism, there was possibility that the function of the metaboreceptor was deteriorated because the core temperature increased due to high temperature relaxed the cutaneous blood vessels which increased TVC.

It has been known that the exposure to a hyperthermic environment increases the catecholamine density in the blood or have no effect (Brenner et al. 1997; Powers et al. 1982). Our results revealed that the density of catecholamine was significantly increased at resting. Decreased blood pressure at resting is perceived by arterial baroreflex and the sympathetic nerves (DiCarlo and Bishop 1992). Therefore, the decreased blood pressure in the hyperthermic environment might have increased the sympathetic nerves by the adverse effect of the arterial baroreflex which then increased the concentration of catecholamine. Linnane et al. (2004) and Furtado et al. (2007) considered that different results on this could be due to differences in subjects' characteristics and core temperatures. The concentration of lactate in the blood is the primary metabolite to arouse the blood vessel relaxation. The present study suggests the possibility that the high concentration of lactate might have caused the decrease in blood pressure at resting through relaxing peripheral blood vessels. A high correlation between MAP increase during the isometric handgrip exercise and the amount of $\mathrm{K}^{+}$released during exercise has been reported (Ooue et al. 2013). However, this study suggests that low $\mathrm{K}^{+}$concentration in the hyperthermic environment might have decreased the blood pressure at rest. Powers et al. (1982) reported that the concentration of catecholamine in the blood and SNA were significantly 

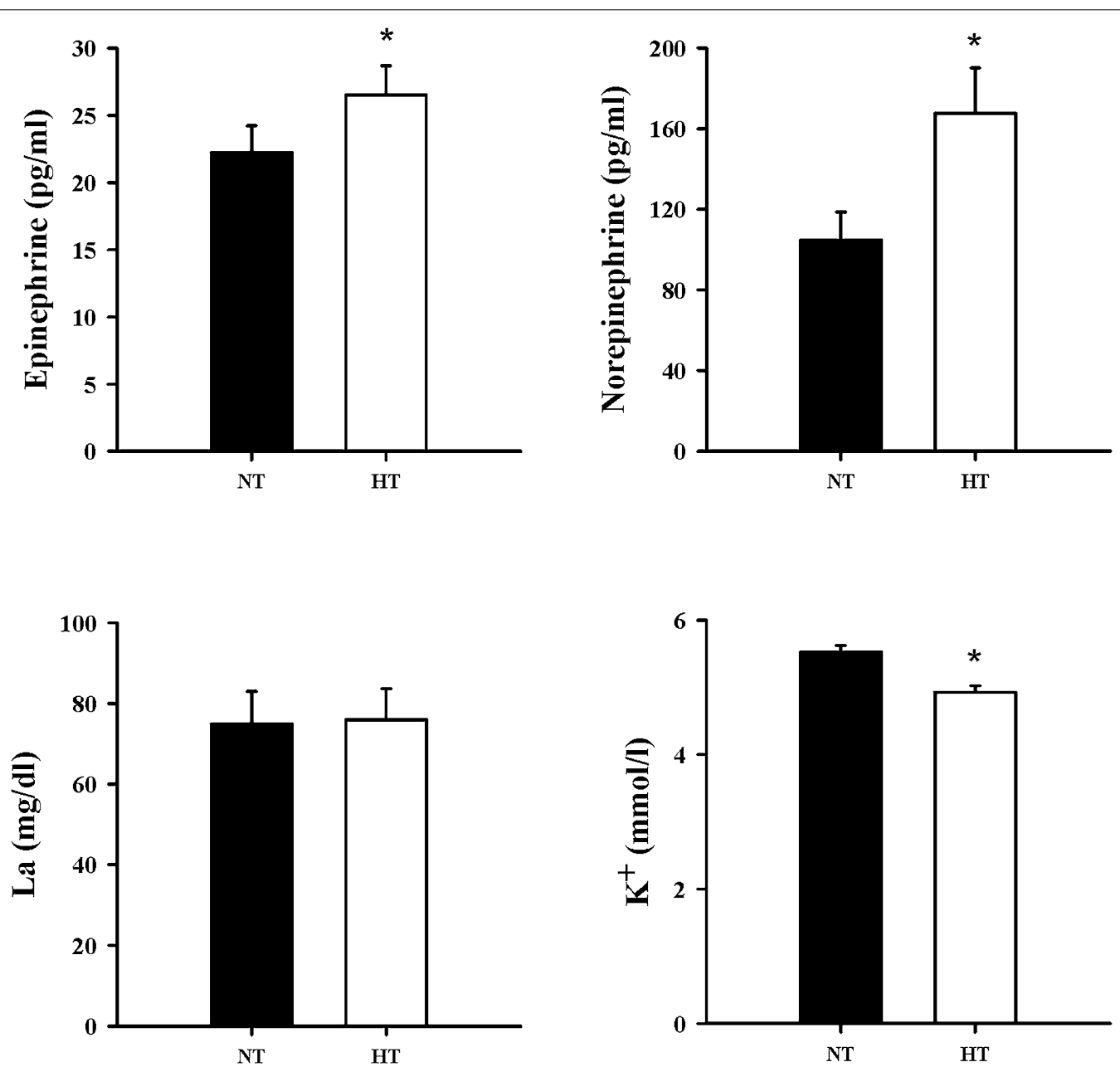

Fig. 4 Epinephrine, norepinephrine, La, $\mathrm{K}^{+}$concentrations in the normothermic or hyperthermic environment at PEMl; NT normothermic environment, HT hyperthermic environment; ${ }^{*}$ significant at $p<0.05$ compared to the normothermic environment

increased in a hyperthermic environment. This study measured the catecholamine in the blood during PEMI to stimulate the metaboreceptor immediately after exercise and found that the level of catecholamine was significantly increased. Increased SNA was also found after stimulation of the metaboreceptor. It has been reported that the La concentration in the blood during exercise between normal temperature and hyperthermic environment is not significantly different (Backx et al. 2000; Falk et al. 1998). Our study also found no difference in the concentration of lactate in the blood between the two environments. According to a previous research (Daley et al. 2002), MAP increase is highly correlated with the amount of released $\mathrm{K}^{+}$during exercise. Therefore, the decreased blood pressure during PEMI in the hyperthermic environment might have resulted from low $\mathrm{K}^{+}$ concentration.

This study derived a conclusion based on results of cardiovascular response by metaboreceptor stimulation during SHE and PEMI in the normothermic and the hyperthermic environments targeting college basketball players. Although the blood pressure significantly decreased at rest in the hyperthermic environment compared to that in the normothermic environment, there was no significant difference in the blood pressure response during SHE in the hyperthermic environment compared to that in the normothermic environment. In addition, the blood pressure increase appeared to be low in the hyperthermic environment than that in the normothermic environment. This study found that the adverse effect of the metaboreceptor was not increased SNA but increased TVC.

\section{Conclusions}

College basketball players who have high physical fitness possess high sensitivity of arterial baroreflex and metaboreceptor stimulation which could increase vasoconstriction toward skin in a hyperthermic environment. The 
blood pressure was less increased because the arterial baroreflex could not offset peripheral vasodilation.

\begin{abstract}
Abbreviations
HR: heart rate; SV: stroke volume; CO: cardiac output; TVC: total vascular conductance; TPR: total peripherial resistance; BMI: body mass index; SBP: systolic blood pressure; DBP: diastolic blood pressure; MAP: mean arterial blood pressure; BP: blood pressure; MVC: maximal voluntary contraction; SHE: static handgrip exercise; PEMI: post exercise muscle ischemia; SNA: sympathetic nerve activity; BSA: body surface area; HPLC: high-performance liquid chromatography; La: lactic acid; $\mathrm{K}^{+}$: potassium.
\end{abstract}

\section{Authors' contributions}

All authors contributed equally to this work. JKK and HGK designed the study. HN gave technical support and conceptual advice. HMC, SL and KAK developed stimuli, gathered behavioural pilot data, and conducted behavioural data analysis. HMC and KAK performed dynamics simulations. MJC interpreted the data. JKK and HMC wrote the manuscript. All authors read and approved the final manuscript.

\section{Authors' information}

H.G.K. obtained a Ph.D. in Exercise Physiology Studies from KyungHee University of Graduated School of Physical Education in 2014, and is currently working as a Head Coach of College Basketball Team at KyungHee University. Recent research interests include dietary supplement, Polyphenol, basketball athletes, and exercise performance. J.K.K. obtained a Ph.D. in Circulation Physiology Studies from Wayne State University of Department of Medical School in 2006, and is currently an Associated Professor of Graduate School of Physical Education at KyungHee University. Professor Kim's works include 'Cardiovascular Responses in Chronic Heart Diseases,', What is the Risk Factor of Boderline Hypertention and Hypertension' and so on. Recent research interests include dietary supplements, Polyphenol, hemodynamic responses, exercise pressor reflex, sympathetic nerve activity, catecolamine, Metabolites responses, and acute workload exercise. H.N. obtained a Ph.D. in Exercise Prescription Studies from Tsukuba University of Department of Exercise Performance Laboratory in 1998, and is currently a Professor of Graduate School of Physical Education at KyungHee University. Professor Nho's works include 'Applied Science of Exercise Programs in Elderly People', 'What is the Impacts of Falls prevention with Elderly People' and so on. Recent research interests include aging index for physical fitness, chronic exercise program, and aging. S.L. obtained a Ph.D. in Exercise Prescription for Elderly from Nagoya University of National Institute of Fitness and Sports in 2010, and is currently a Research Fellow of National Center for Geriatrics and Gerontology. Lee's works include 'Exercise on Strength and Power in Untrained and Trained healthy older adults', 'Aging Prevention' and so on. Recent research interests include aging index for physical functions and cognitive impairment in community-dwelling elderly population. K.A.K. obtained a Ph.D. in Exercise Physiology Studies from KyungHee University of Graduated School of Physical Education in 2013, and is currently a Research Fellow of Department of Exercise Performance Laboratory at KyungHee University. Kim's works include 'Cardiovascular Responses in Chronic Heart Diseases', 'What is the Risk Factor of Normotension and Prehypertension trough Acute Exercise' and so on. Recent research interests include dietary supplements, Polyphenol, hemodynamic responses, acute exercise, and exercise performance. M. J. C. obtained a Ph.D. in Special Physical Education from Universität zu Köln in 1988, and is currently a Professor of Graduate School of Physical Education at KyungHee University. Chang's works include 'Physical Fitness with Physical and Mental impairments','Related impairment Prevention' and so on. Recent research interests include physical and mental impairments index for physical and cognitive function in disoder population. H.M.C. obtained a Ph.D. in Sports Medicine Studies from Kyung Hee University of Graduated School of Physical Education in 2005, and is currently an Assistant Professor of Graduate School of Physical Education at KyungHee University. Choi's works include 'Cardiovascular Responses by Intake Dietary Supplements with Sports Athletes and Chronic Heart Diseases', 'What is the Risk Factor of Boderline Hypertention' and so on. Recent research interests include dietary supplements, Polyphenol, cardiovascular responses, exercise pressor reflex, sympathetic nerve activity, exercise performance, catecolamine and metabolites responses, and acute workload exercise.

\section{Acknowledgements}

We would like to thank the college basketball players for their time. This work was supported by a grant from the Kyung Hee University (\#20131569).

\section{Competing interests}

The authors declare that they have no competing interests.

Received: 14 December 2015 Accepted: 10 March 2016

Published online: 24 March 2016

\section{References}

Amano T, Ichinose M, Koga S, Inoue Y, Nishiyasu T, Kondo N (2011) Sweating responses and the muscle metaboreflex under mildly hyperthermic conditions in sprinters and distance runners. J Appl Physiol 111:524-529

Armstrong R, Delp M, Goljan E, Laughlin M (1987) Progressive elevations in muscle blood flow during prolonged exercise in swine. J Appl Physiol 63:285-291

Backx K, Mc Naughton L, Crickmore L, Palmer G, Carlisle A (2000) Effects of differing heat and humidity on the performance and recovery from multiple high intensity, intermittent exercise bouts. Int J Sports Med 21:400-405

Bogert LW, van Lieshout JJ (2005) Non-invasive pulsatile arterial pressure and stroke volume changes from the human finger. Exp Physiol 90:437-446

Brenner I, Zamecnik J, Shek P, Shephard R (1997) The impact of heat exposure and repeated exercise on circulating stress hormones. Eur J Appl Physiol Occup Physiol 76:445-454

Choi HM, Stebbins CL, Lee OT, Nho H, Lee JH, Chun JM, Kim KA, Kim JK (2013) Augmentation of the exercise pressor reflex in prehypertension: roles of the muscle metaboreflex and mechanoreflex. Appl Physiol Nutr Metab 38:209-215

Crandall CG (2000) Carotid baroreflex responsiveness in heat-stressed humans. Am J Physiol Heart Circ Physiol 279:H1955-H1962

Crandall C, González-Alonso J (2010) Cardiovascular function in the heatstressed human. Acta Physiol 199:407-423

Cui J, Wilson TE, Crandall CG (2004) Muscle sympathetic nerve activity during lower body negative pressure is accentuated in heat-stressed humans. $J$ Appl Physiol 96:2103-2108

Daley JC, Hogeman CS, Sinoway LI (2002) Venous plasma potassium is not associated with maintenance of the exercise pressor reflex in humans. Am J Physiol Regul Integr Comp Physiol 282:R1608-R1612

Damato AN, Lau SH, Stein E, Haft Jl, Kosowsky B, Cohen SI (1968) Cardiovascular response to acute thermal stress (hot dry environment) in unacclimatized normal subjects. Am Heart J 76:769-774

DiCarlo SE, Bishop VS (1992) Onset of exercise shifts operating point of arterial baroreflex to higher pressures. Am J Physiol Heart Circ Physiol 262:H303-H307

Falk B, Radom-Isaac S, Hoffmann J, Wang Y, Yarom Y, Magazanik A, Weinstein Y (1998) The effect of heat exposure on performance of and recovery from high-intensity, intermittent exercise. Int J Sports Med 19:1-6

Furtado AL, Craig BN, Chard JT, Zaloom VA, Chu H (2007) Cooling suits, physiological response, and task performance in hot environments for the power industry. Int J Occup Saf Ergon 13:227-239

Goldberg M, Boutcher S, Boutcher Y (2011) The effect of 4 weeks of aerobic exercise on vascular and baroreflex function of young men with a family history of hypertension. J Hum Hypertens 26:644-649

Gulli G, Cevese A, Cappelletto P, Gasparini G, Schena F (2003) Moderate aerobic training improves autonomic cardiovascular control in older women. Clin Auton Res 13:196-202

Hayes SG, Kaufman MP (2001) Gadolinium attenuates exercise pressor reflex in cats. Am J Physiol Heart Circ Physiol 280:H2153-H2161

Hayes SG, Kindig AE, Kaufman MP (2005) Comparison between the effect of static contraction and tendon stretch on the discharge of group III and IV muscle afferents. J Appl Physiol 99:1891-1896

Keller DM, Cui J, Davis SL, Low DA, Crandall CG (2006) Heat stress enhances arterial baroreflex control of muscle sympathetic nerve activity via increased sensitivity of burst gating, not burst area, in humans. J Physiol 573:445-451 
Kim JK, Sala-Mercado JA, Hammond RL, Rodriguez J, Scislo TJ, O'Leary DS (2005a) Attenuated arterial baroreflex buffering of muscle metaboreflex in heart failure. Am J Physiol Heart Circ Physiol 289:H2416-H2423

Kim JK, Sala-Mercado JA, Rodriguez J, Scislo TJ, O'Leary DS (2005b) Arterial baroreflex alters strength and mechanisms of muscle metaboreflex during dynamic exercise. Am J Physiol Heart Circ Physiol 288:H1374-H1380

Kondo N, Tominaga H, Shibasaki M, Aoki K, Okada S, Nishiyasu T (2000) Effects of exercise intensity on the sweating response to a sustained static exercise. J Appl Physiol 88:1590-1596

Kondo N, Yanagimoto S, Nishiyasu T, Crandall CG (2003) Effects of muscle metaboreceptor stimulation on cutaneous blood flow from glabrous and nonglabrous skin in mildly heated humans. J Appl Physiol 94:1829-1835

Laughlin MH, Armstrong R (1983) Rat muscle blood flows as a function of time during prolonged slow treadmill exercise. Am J Physiol Heart Circ Physiol 244:H814-H824

Linnane D, Bracken R, Brooks S, Cox V, Ball D (2004) Effects of hyperthermia on the metabolic responses to repeated high-intensity exercise. Eur J Appl Physiol 93:159-166

Minson CT, Wladkowski SL, Cardell AF, Pawelczyk JA, Kenney WL (1998) Age alters the cardiovascular response to direct passive heating. J Appl Physiol 84:1323-1332

Ooue A, Sato K, Hirasawa A, Sadamoto T (2013) Superficial venous vascular response of the resting limb during static exercise and postexercise muscle ischemia. Appl Physio Nutr Metabol 38:941-946

Powers SK, Howley ET, Cox R (1982) A differential catecholamine response during prolonged exercise and passive heating. Med Sci Sports Exerc 14:435-439

Raczak G, Danilowicz-Szymanowicz L, Kobuszewska-Chwirot M, Ratkowski W, Figura-Chmielewska M, Szwoch M (2006) Long-term exercise training improves autonomic nervous system profile in professional runners. Kardiol Pol 64:135-140
Ray CA, Wilson TE (2004) Comparison of skin sympathetic nerve responses to isometric arm and leg exercise. J Appl Physiol 97:160-164

Rowell LB, Blackmon JR (1986) Lack of sympathetic vasoconstriction in hypoxemic humans at rest. Am J Physiol 251(3 Pt 2):H562-H570

Rowell LB, Brengelmann GL, Murray JA (1969) Cardiovascular responses to sustained high skin temperature in resting man. J Appl Physiol 27:673-680

Rowell LB, Saltin B, Kiens B, Christensen NJ (1986) Is peak quadriceps blood flow in humans even higher during exercise with hypoxemia. Am J Physiol Heart Circ Physiol 251:H1038-H1044

Saito M, Naito M, Mano T (1990) Different responses in skin and muscle sympathetic nerve activity to static muscle contraction. J Appl Physiol 69:2085-2090

Sausen M, Delaney E, Stillabower M, Farquhar WB (2009) Enhanced metaboreflex sensitivity in hypertensive humans. Eur J Appl Physiol 105:351-356

Shibasaki M, Kondo N, Crandall CG (2001) Evidence for metaboreceptor stimulation of sweating in normothermic and heat-stressed humans. J Physiol 534:605-611

Sinoway L, Prophet S, Gorman I, Mosher T, Shenberger J, Dolecki M, Briggs R, Zelis R (1989) Muscle acidosis during static exercise is associated with calf vasoconstriction. J Appl Physiol 66:429-436

Stebbins CL, Brown B, Levin D, Longhurst JC (1988) Reflex effect of skeletal muscle mechanoreceptor stimulation on the cardiovascular system. J Appl Physiol 65:1539-1547

Vissing SF, Hjortso EM (1996) Central motor command activates sympathetic outflow to the cutaneous circulation in humans. J Physiol 492:931-939

Vissing SF, Scherrer U, Victor RG (1991) Stimulation of skin sympathetic nerve discharge by central command. differential control of sympathetic outflow to skin and skeletal muscle during static exercise. Circ Res 69:228-238

Wilmore JH, Costill DL, Larry KW (2008) Physiology of sport and exercise, 4th edn. Human Kinetic, Champaign

\section{Submit your manuscript to a SpringerOpen ${ }^{\odot}$ journal and benefit from:}

- Convenient online submission

- Rigorous peer review

- Immediate publication on acceptance

- Open access: articles freely available online

- High visibility within the field

- Retaining the copyright to your article

Submit your next manuscript at $>$ springeropen.com 